$\underline{\text { Research Article }}$

\title{
Antimicrobial susceptibility pattern of blood culture isolates from patients with suspected neonatal sepsis in a tertiary care hospital in Pakistan
}

\author{
T Ghafoor ${ }^{1}$, A Hussanain ${ }^{1}$, MM Qureshi ${ }^{1}$, T Mehmood $^{1}$, L Ali $^{1}$ \\ Sri Lankan Journal of Infectious Diseases 2020 Vol.10 (1):30-37 \\ DOI: http://dx.doi.org/10.4038/sljid.v10i1.8244
}

\begin{abstract}
Introduction: Neonatal septicemia is one of the commonest reasons for neonatal morbidity and mortality in developing countries. Knowledge of microbial flora and their susceptibility will help paediatricians decide on empirical treatment of neonatal sepsis.
\end{abstract}

Objective: To determine the antimicrobial susceptibility of blood culture isolates from patients with suspected neonatal sepsis in a tertiary care hospital in Pakistan.

Study design: A laboratory based prospective study was carried out in the Department of Pathology, Combined Military Hospital, Sialkot, from March 2017 to February 2019.

Methods: Blood culture and sensitivity testing was carried out on patients admitted for suspected neonatal sepsis from March 2017 to February 2019. Antimicrobial susceptibility testing of blood culture isolates was carried out by disk diffusion method using the Clinical Laboratory Standard Institute (CLSI) guidelines.

Results: During the study period, 345 blood cultures from 345 neonates (age range 1 day-28 days; mean age 13 days) were received by the laboratory, of which76 were culture positive. Gram negative bacilli were isolated from 44 cultures and Gram positive cocci from the remaining 32. Staphylococcus aureus was the commonest isolate $(\mathrm{n}=28)$ followed by Escherichia coli $(\mathrm{n}=10)$, Klebsiella pneumoniae $(\mathrm{n}=9)$ and Acinetobacter spp. $(\mathrm{n}=8)$. Methicillin resistant $S$. aureus (MRSA) constituted $(\mathrm{n}=19) 25 \%$ of culture positive isolates. Pseudomonas aeruginosa was isolated from six patients. Serratia spp., Enterobacter spp. and Enterococcus spp. from four patients each and Proteus spp. isolated from three patients. Linezolid was the most effective antimicrobial against the isolated Gram positive cocci, with $93.7 \%$ sensitivity demonstrated by MRSA, methicillin sensitive $S$. aureus and enterococcus spp. followed by sensitivity to clindamycin at $92.8 \%$. Among Gram negative isolates, more than $80 \%$ of E. coli, K. pneumonia

${ }^{1}$ Combined Military Hospital (CMH) Sialkot/ National University of Medical Sciences (NUMS) Pakistan Address for correspondence: Dr. Tahir Ghafoor, Consultant Microbiologist. Department of Pathology, Combined Military Hospital (CMH) Sialkot, Pakistan. Telephone: +923317013950 Email: drtahirghafoor@gmail.com

https://orcid.org/0000-0002-0848-763X

Received 27 April 2019 and revised version accepted 27 August 2019

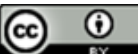

This an open-access article distributed under the terms of the Creative Commons Attribution License, which permits unrestricted use, distribution, and reproduction in any medium, provided the original author and source are credited. 
and Acinetobacter spp. were multidrug resistant. Susceptibility to polymyxin-B and tigecycline was shown by $88 \%$ and $71 \%$ of these isolates.

Conclusion: A high degree of antibiotic resistance was observed in both Gram positive and Gram negative isolates which reflects a dire need for culture facilities and antimicrobial susceptibility testing in hospitals in Pakistan. No group B $\beta$ hemolytic streptococci were isolated, most likely due to predominantly late onset neonatal sepsis in this cohort.

Keywords: Neonatal sepsis, Antimicrobial susceptibility, Neonatal Intensive Care Unit (NICU)

\section{Introduction}

The presence of a positive blood culture historically constitutes the "gold standard" for diagnosis of neonatal sepsis. ${ }^{1}$ Neonatal sepsis is a clinical condition showing systemic signs and symptoms due to bacteremia in the first month of life. Neonatal sepsis may also be a nosocomial infection which, by definition, is established within 48 to 72 hours after admission to a hospital. ${ }^{2}$ Neonatal sepsis is frequently seen in neonatal intensive care units (NICU) and involves multiple factors including birth weight, sex, gestational age, parenteral nutrition, severity of disease, use of antimicrobials, repeated invasive procedures such as central venous catheterization, assisted ventilation as well as immunodeficiency during the neonatal period. ${ }^{3-5}$ The World Health Organization (WHO) estimates 1.6 million neonatal deaths per year occur globally due to sepsis including $40 \%$ of all neonatal deaths that occur in developing countries. ${ }^{6}$

Neonatal sepsis is life threatening if appropriate treatment is not given in time. Moreover, due to its nonspecific signs and symptoms, clinical diagnosis of this disease can be challenging. Microorganisms causing neonatal sepsis may show diversity in different countries and in hospitals of the same region and are of concern due to the presence of multidrug resistance. ${ }^{7}$ Antibiotics are among the most frequently used medications in the NICU. ${ }^{8}$ Use of antibiotics varies in different NICUs which necessitates implementation of antibiotic stewardship. ${ }^{9,10}$ Pediatricians and neonatologists must be made aware that starting antibiotics in certain circumstances may be more harmful than beneficial. ${ }^{11}$ While prompt antibiotic therapy for possible infections in this vulnerable population is crucial for a good outcome, inadequate or inappropriate use of antibiotics results in a rising trend of multidrug resistant bacteria. ${ }^{12,13}$ Antibiotic susceptibility patterns vary geographically depending upon the prevalent local pathogens and common antibiotics being used in neonatal units. ${ }^{14}$ Emergence of antimicrobial resistance has become an alarming public health concern with non-responsiveness to available antibiotics.

Effective management of neonatal sepsis requires an understanding of the pathogenesis of neonatal sepsis along with up-to-date information on possible aetiological agents and their antibiotic sensitivity profile. For prompt diagnosis of neonatal sepsis, bacteriological culture of blood and representative samples plays an important role. A wide range of pathogens including $S$. aureus, E. coli, K. pneumoniae, Proteus mirabilis, Enterobacter spp., P. aeruginosa and Enterococcus spp. may cause neonatal sepsis. The wide variety of resistance mechanisms utilized by these bacteria has led to the emergence of multidrug resistant (MDR) bacteria which has forced clinicians to switch over to carbapenems, vancomycin and colistin.

Knowledge of common pathogens causing neonatal sepsis and their antimicrobial susceptibility profiles, nationally as well as in individual health care institutions, is of utmost importance to select 
appropriate empirical antibiotic therapy and decrease neonatal morbidity and mortality. This study aimed to provide the antibiogram of pathogens causing neonatal sepsis in our setting. This would help in rational use of antibiotics as well as contribute to national data, assisting in formulating effective and up-to-date antibiotic guidelines for local and national use in neonatal sepsis.

\section{Methods}

This laboratory-based study was carried out at the Microbiology Department of the Combined Military Hospital (CMH) Sialkot, Pakistan. All blood cultures received from patients admitted to the NICU from March 2017 to February 2019 with suspected neonatal sepsis, regardless of gestational age and weight were processed and culture positive specimens were included in this study. Repeat samples from the same patient showing growth of similar microorganism and similar sensitivity pattern were excluded.

One to two $\mathrm{ml}$ of blood was collected aseptically before starting antimicrobial therapy into qualitycontrolled Brain Heart Infusion broth (BHI) at a blood:BHI ratio of $1: 5$ and incubated at $35^{\circ} \mathrm{C} \pm$ 2 for 24 hours. Blood cultures were then subcultured on Sheep Blood Agar (SBA), MacConkey agar and chocolate agar daily for 7 days. $S$. aureus (ATCC 25923), E. coli (ATCC 25922) and $P$. aeruginosa (ATCC 27853) were used as control strains for quality control of SBA, MacConkey agar, chocolate agar and Mueller-Hinton agar (MHA) plates. Blood agar and MacConkey agar plates were incubated aerobically, while chocolate agar plates were incubated in a $\mathrm{CO}_{2}$ enriched humid atmosphere using a candle jar at $35^{\circ} \mathrm{C} \pm 2$ for $24-48$ hours. Blood culture bottles which showed no growth after incubation for 7 days were reported as negative.

Identification of the microorganisms was done using Gram staining, biochemical tests and serology. Analytical profile index API-20E (Biomerieux, France) was used to identify Enterobacteriaceae and associated organisms and API-20NE (Biomerieux, France) to identify Acinetobacter spp. and $P$. aeruginosa according to the manufacturer's directions. For the confirmation of $S$. aureus, gram staining, catalase test, DNase test and coagulase test were performed. Enterococcus spp. were identified using the Gram stain, catalase test, arabinose (1\%), bile esculin (40\%) and $\mathrm{NaCl}$ broth (6.5\%) tests.

Antibacterial susceptibility of the isolates with $0.5 \mathrm{McFarland}$ standards was done on prepared MHA (MAST Diagnostics, UK) using the Kirby-Bauer disk diffusion method as per the CLSI protocol. Commercially available standard antibiotic discs (Oxoid UK) were used. The zones of inhibition were measured and recorded according to the CLSI guidelines. ${ }^{15}$ Amikacin $(30 \mu \mathrm{g})$, imipenem $(10 \mu \mathrm{g})$, gentamicin $(30 \mu \mathrm{g})$, ceftriaxone $(30 \mu \mathrm{g})$, amoxicillin / clavulanic acid (20/10 $\mu \mathrm{g})$, doxycycline $(30 \mu \mathrm{g})$, ciprofloxacin $(5 \mu \mathrm{g})$, tigecycline $(15 \mu \mathrm{g})$, trimethoprim / sulfamethoxazole $(1.25 / 23.75 \mu \mathrm{g})$, ampicillin $(25 \mu \mathrm{g})$, linezolid $(30 \mu \mathrm{g})$, piperacillin / tazobactam $(100 / 10 \mu \mathrm{g})$, cefepime $(30 \mu \mathrm{g})$, and cefoperazone / sulbactam $(75 / 30 \mu \mathrm{g})$ were used for susceptibility testing while cefoxitin $(30 \mu \mathrm{g})$ was used for MRSA screening. Vancomycin could not be tested due to non-availability of e-strips for measuring MICs.

The data obtained was entered in Statistical Package for Social Sciences (SPSS) version 17 for statistical evaluation. Descriptive statistics including mean and standard deviation for age, percentages of variables including gender and antimicrobial susceptibility pattern of bacteria isolated in samples were calculated. 


\section{Results}

During the two year study period, 345 samples were submitted. Excluding coagulase negative staphylococci (CONS), 76 (22\%) yielded growth, of which 30 (39.5\%) were from female patients while $46(60.5 \%)$ were from males giving a male to female ratio of $1: 1.5$. The mean age of patients was 13 days, ranging from 1 to 28 days. Gram negative bacilli constituted the majority of isolates $(\mathrm{n}=44 ; 57.9 \%)$ with Gram positive cocci isolated in $32(42.1 \%)$ of patients. E. coli was the most

Table 1: Frequency of bacteria isolated from blood culture in patients with neonatal sepsis $(n=76)$

\begin{tabular}{|c|c|c|c|c|c|c|c|c|c|c|}
\hline 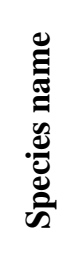 & $\begin{array}{l}\ddot{8} \\
\dot{8}\end{array}$ & 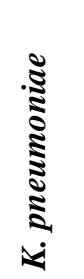 & 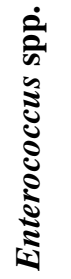 & 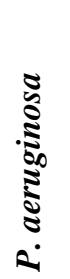 & 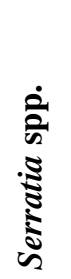 & 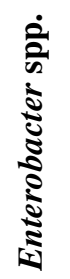 & 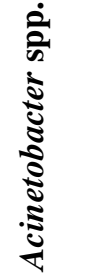 & 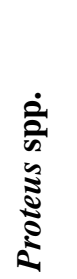 & 岕 & 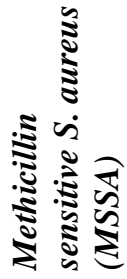 \\
\hline No & 10 & 9 & 4 & 6 & 4 & 4 & 8 & 3 & 19 & 9 \\
\hline$\%$ & 13 & 11.8 & 5.3 & 7.9 & 5.3 & 5.3 & 10.5 & 3.9 & 25 & 11.8 \\
\hline
\end{tabular}
common Gram negative isolate $(\mathrm{n}=10 ; 13.1 \%)$. $S$. aureus was the commonest Gram positive isolate $(\mathrm{n}=28$; $36.8 \%)$. The frequency of culture positive isolates in patients with suspected neonatal sepsis is shown in Table 1.

More than $90 \%$ of Gram positive isolates were susceptible to linezolid and clindamycin while Gram negative isolates, especially the Enterobacteriaceae group exhibited excellent susceptibility to polymyxin-B, tigecycline, carbapenems and amikacin. The sensitivity pattern of all blood culture isolates is listed in Tables 2 and 3.

Table 2: Susceptibility pattern of Gram positive isolates $(n=32)$

\begin{tabular}{|c|c|c|c|c|c|c|}
\hline \multirow[b]{2}{*}{ Antibiotics } & \multicolumn{2}{|c|}{$\begin{array}{c}\text { MRSA } \\
19\end{array}$} & \multicolumn{2}{|c|}{$\begin{array}{c}\text { MSSA } \\
9\end{array}$} & \multicolumn{2}{|c|}{$\begin{array}{c}\text { Enterococcus spp } \\
4\end{array}$} \\
\hline & $\mathbf{S}$ & $\mathbf{R}$ & $\mathbf{S}$ & $\mathbf{R}$ & $\mathbf{S}$ & $\mathbf{R}$ \\
\hline Ampicillin & NT & NT & NT & NT & 1 & 3 \\
\hline Gentamicin & 6 & 13 & 6 & 3 & NT & NT \\
\hline Amikacin & 9 & 10 & 9 & 0 & NT & NT \\
\hline Trimethoprim/ sulfamethoxazole & 6 & 13 & 2 & 7 & NT & NT \\
\hline Doxycycline & 12 & 7 & 4 & 5 & 2 & 2 \\
\hline Ciprofloxacin & 6 & 13 & 2 & 7 & 2 & 2 \\
\hline Clindamycin & 17 & 2 & 9 & 0 & NT & NT \\
\hline Erythromycin & 2 & 17 & 2 & 7 & NT & NT \\
\hline Linezolid & 18 & 1 & 9 & 0 & 3 & 1 \\
\hline
\end{tabular}

$\mathrm{n}=$ number of isolates, $\mathrm{S}=$ sensitive, $\mathrm{R}=$ resistant; NT- Not tested as per CLSI guidelines 
Table 3: Susceptibility pattern of Gram negative isolates $(n=44)$

\begin{tabular}{|c|c|c|c|c|c|c|c|c|c|c|c|c|c|c|c|}
\hline & $\begin{array}{l}\dot{\tilde{\sigma}} \\
\dot{\delta}\end{array}$ & & 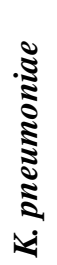 & & 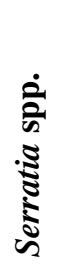 & & & $\frac{2}{n}$ & & & 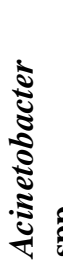 & & छั & & 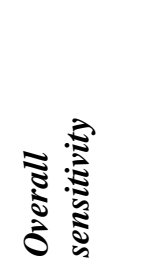 \\
\hline $\mathrm{n}$ & & & & & & & & & & & & & & & \\
\hline Antibiotics & $\mathbf{S}$ & $\mathbf{R}$ & $\mathbf{S}$ & $\mathbf{R}$ & $\mathbf{S}$ & $\mathbf{R}$ & $\mathbf{S}$ & $\mathbf{R}$ & $\mathbf{S}$ & $\mathbf{R}$ & $\mathbf{S}$ & $\mathbf{R}$ & $\mathbf{S}$ & $\mathbf{R}$ & $\begin{array}{l}\text { sensitive / } \\
\text { No. tested }\end{array}$ \\
\hline Ampicillin & 0 & 10 & NT & NT & NT & NT & NT & NT & NT & NT & NT & NT & NT & NT & $0 / 10$ \\
\hline Gentamicin & 2 & 8 & 2 & 7 & 0 & 0 & 1 & 2 & 2 & 2 & 3 & 5 & 2 & 4 & $12 / 40$ \\
\hline Amikacin & 5 & 5 & 3 & 6 & 2 & 2 & 0 & 3 & 2 & 2 & 5 & 3 & 2 & 4 & $19 / 44$ \\
\hline $\begin{array}{l}\text { Amoxicillin / } \\
\text { clavulanate }\end{array}$ & 0 & 10 & 0 & 9 & NT & NT & 1 & 2 & NT & NT & NT & NT & NT & NT & $1 / 21$ \\
\hline Imipenem & 4 & 6 & 2 & 8 & 1 & 3 & 2 & 1 & 3 & 1 & 1 & 7 & 2 & 4 & $15 / 44$ \\
\hline Meropenem & 3 & 7 & 4 & 6 & 1 & 3 & 2 & 1 & 3 & 1 & 2 & 6 & 2 & 4 & $17 / 44$ \\
\hline $\begin{array}{l}\text { Cefoperazone / } \\
\text { sulbactam }\end{array}$ & 3 & 7 & 0 & 9 & 1 & 3 & 2 & 1 & 3 & 1 & 1 & 7 & 4 & 2 & $14 / 44$ \\
\hline $\begin{array}{l}\text { Piperacillin / } \\
\text { tazobactam }\end{array}$ & 2 & 8 & 1 & 8 & 2 & 2 & 1 & 2 & 2 & 2 & 0 & 8 & 4 & 2 & $12 / 44$ \\
\hline $\begin{array}{l}\text { Trimethoprim / } \\
\text { sulfamethoxazole }\end{array}$ & 0 & 10 & 0 & 9 & 2 & 2 & 1 & 2 & 2 & 2 & 0 & 8 & NT & NT & $5 / 38$ \\
\hline Doxycycline & 4 & 6 & 2 & 7 & 2 & 2 & NT & NT & 3 & 1 & 2 & 6 & NT & NT & $13 / 35$ \\
\hline Ciprofloxacin & 1 & 9 & 0 & 9 & 0 & 4 & 2 & 1 & 3 & 1 & 0 & 8 & 2 & 4 & $8 / 44$ \\
\hline Ceftriaxone & 2 & 8 & 1 & 8 & 0 & 4 & 1 & 2 & 1 & 3 & 1 & 7 & NT & NT & $6 / 38$ \\
\hline Cefepime & NT & NT & NT & NT & NT & NT & NT & NT & NT & NT & NT & NT & 3 & 3 & $3 / 6$ \\
\hline Tigecycline & 7 & 3 & 6 & 3 & 2 & 2 & NT & NT & 3 & 1 & 6 & 2 & NT & NT & $24 / 35$ \\
\hline Polymyxin-B & 10 & 0 & 8 & 1 & NT & NT & NT & NT & 4 & 0 & 7 & 1 & 6 & 0 & $35 / 37$ \\
\hline
\end{tabular}

NT - Not tested as per CLSI guidelines

\section{Discussion}

Pakistan is the 7th most populous country in world and number three among those countries in neonatal deaths with 298000 deaths occurring annually. ${ }^{16}$ In Pakistan, the neonatal mortality rate is $49 / 1000$ live births and we account for $7 \%$ of global neonatal deaths. ${ }^{17}$ Among developing countries like Pakistan where high-tech diagnostic facilities are sparse, newer mutant bacterial strains are also emerging making it more difficult to control infections. Effective management of patients suffering from neonatal sepsis requires identification of the bacterial isolate along with selection of an appropriate and effective antibiotic for appropriate treatment.

Microbial resistance to antibiotics is an ongoing serious problem in the treatment of neonatal sepsis. This study highlights the high rate of antimicrobial resistance among bacterial pathogens isolated from blood cultures of neonates admitted to the NICU and confirms that Sialkot and surrounding area is no exception to progressive antimicrobial resistance in major bacterial pathogens. Surprisingly, Group B $\beta$ hemolytic streptococci were not isolated in our study. One possible reason is that most of the patients in our study were probable late onset neonatal sepsis. 
Similar to our results, most previous studies also emphasized the major role of $E$. coli, $K$. pneumoniae and $S$. aureus as the main microorganisms causing neonatal sepsis. ${ }^{18}$ The causative agents of neonatal sepsis change over time and may vary from place to place. In the current study, among Gram negative organisms, E. coli was the most commonly isolated followed by $K$. pneumoniae while among Gram positive organisms $S$. aureus, especially MRSA was the most frequent. This finding is consistent to a previous study in a Pakistani population. ${ }^{19}$ Shrestha et al. also identified $E$. coli as the predominant organism causing neonatal sepsis. ${ }^{20}$ Resistance of sepsis related pathogens to routinely used antibiotics has been reported widely. The high levels of resistance to gentamicin in this study are comparable to a Pakistani study by Aftab et al.(2006) and an Iranian study by Marzban A et al.(2010) ${ }^{19,21}$ In our study, isolates showed considerable resistance to ceftriaxone. This emerging resistance to the third generation cephalosporins is also supported by studies from Pakistan ${ }^{22}$ and Nepal. ${ }^{23}$ Our study showed that $84 \%$ of Gram negative rods were resistant to ceftriaxone as compared $66.9 \%$ observed in another Pakistani study done in $2017 .^{24}$ This rising trend of ceftriaxone resistance by common pathogens may be due to the irrational use of this drug in Pakistan. In our study, amikacin was the most effective aminoglycoside for both Gram positive and Gram negative microorganisms which correlates with the findings of Muley et al. ${ }^{25}$ Not unexpectedly, our study demonstrated a high level of resistance to commonly used antibiotics like ampicillin, amoxicillin clavulanic acid and gentamicin in both Gram positive and Gram negative pathogens causing neonatal sepsis. A Nepalian study by Nepal HP et al. reported more than $90 \%$ resistance of Gram negative rods to cotrimoxazole which is also in conformity to our study. ${ }^{26}$

An Indian study done in 2017 showed 100\% sensitivity of Pseudomonas spp to colistin and 54\% sensitivity to cefepime, while $S$. aureus showed more than $90 \%$ sensitivity to linezolid and clindamycin, which was also confirmed by our study. ${ }^{27}$ Another study from Pakistan also showed $100 \%$ susceptibility of $S$. aureus to linezolid. ${ }^{28}$ However, in contrast to our results, the Indian study showed less resistance of Enterobacteriaceae to carbapenems and aminoglycosides. ${ }^{26}$ Our study results on Acinetobacter spp. sensitivity to carbapenem and gentamicin are also consistent to those of a study done in Paraguay. ${ }^{29}$ A South African study reported $100 \%$ piperacillintazobactam and $80 \%$ meropenem resistance in Acinetobacter spp which is also comparable to our study results. ${ }^{30}$ The main reason for variation in antibiotic susceptibility pattern might be due to variant pattern of antimicrobial use in different hospitals or to the emergence of multidrug resistant strains as a result of widespread inappropriate use of antibiotics.

In the current study, a larger number of the Enterobacteriaceae were susceptible to tigecycline polymyxin (Table 3) and it is imperative that these drugs should be used with caution and according to susceptibility results in our hospitals.

\section{Conclusion}

S. aureus, E. coli, K. pneumoniae and Acinetobacter spp were the predominant causes of neonatal sepsis in our study which serves as a surveillance of antimicrobial resistance in the NICU for a 2 year period. The study demonstrates a high level of resistance to commonly used first line antibiotics in the hospital and provides information for use and further investigation by the hospital infection control team. Continuing surveillance of antimicrobial resistance is recommended to get 
regular updates on the susceptibility of pathogens causing neonatal sepsis to the broader spectrum antibiotics available for clinical use in Pakistan.

Limitations of study: This study covered only Sialkot and surrounding rural areas. Blood samples could not be segregated on the basis of early and or late onset suspected neonatal sepsis.

Funding: This work was completely supported by Combined Military Hospital (CMH) Sialkot, Pakistan.

Ethical clearance: Permission was obtained from the Hospital Ethics and Research Committee.

Conflict of interest: The material for research purpose was made available by the hospital. However, there were neither conflict of interest of authors with the material provider companies nor any financial or other gains from the companies.

\section{References}

1. Wynn JL, Wong HR, Shanley TP, et al. Time for a neonatal-specific consensus definition for sepsis. Pediatric Critical Care Medicine. 2014; 15(6):523-8. doi: https://doi.org/10.1097/PCC.0000000000000157

2. Garner JS, Jarvis WR, Emori TG, et al. CDC definitions for nosocomial infections. Am J Infect Control 1988; 16:128-40.doi: http://dx.doi.org/10.1016/0196-6553(88)90053-3

3. Softic I, Tahirovic H, Di Ciommo V, et al. Bacterial sepsis in neonates: Single center study in a neonatal intensive care unit in Bosnia and Herzegovina. Acta Med Acad. 2017; 46(1):7-15.

doi: https://doi.org/10.5644/ama2006-124.181

4. Rios VV, Navia BMP, Díaz VM,et al. Risk factors associated with neonatal sepsis. Rev BolPed 2005; 44 (2):87-92. doi:http://www.scielo.org.bo/scielo.php?script=sci_arttext\&pid=S1024-06752005000200004

5. Kan B, Razzaghian HR, Lavoie PM. An immunological perspective on neonatal sepsis. Trends Mol Med 2016; 22(4):290-302. doi: 10.1016/j.molmed.2016.02.001

6. Sarangi KK, Pattnaik D, Mishra SN, et al. Bacteriological profile and antibiogram of blood culture isolates done by automated culture and sensitivity method in a neonatal intensive care unit in a tertiary care hospital in Odisha, India. IJAM, 2015; 2(4):387-92. doi: http://dx.doi.org/10.18203/23493933.ijam20151015

7. Lona RJC, Verdugo RMA, Perez RRO, et al. Etiology and antimicrobial resistance patterns in early and late neonatal sepsis, in a Neonatal Intensive Care Unit. Arch Argent Pediatr 2015; 113(4):31723. doi: https://doi.org/10.5546/aap.2015.317

8. Clark RH, Bloom BT, Spitzer AR, et al. Reported medication use in the neonatal intensive care unit: data from a large national data set. Pediatrics 2006; 117:1979-87. doi: https://doi.org/10.1542/peds.2005-1707

9. Schulman J, Dimand RJ, Lee HC, et al. Neonatal intensive care unit antibiotic use. Pediatrics 2015; 135:826-33.doi: https://doi.org/10.1542/peds.2014-3409

10. Liem TBY, Krediet TG, Fleer A, et al. Variation in antibiotic use in neonatal intensive care units in the Netherlands. J Antimicrob Chemother 2010; 65:1270-5. doi: https://doi.org/10.1093/jac/dkq107

11. Mukhopadhyay S, Puopolo KM. Antibiotic use and mortality among premature infants without confirmed infection-perpetrator or innocent bystander? JAMA Pediatr 2016; 170:1144-6.doi: http://dx.doi.org/10.1001/jamapediatrics.2016.2836

12. Weiss SL, Fitzgerald JC, Balamuth F, et al. Delayed antimicrobial therapy increases mortality and organ dysfunction duration in pediatric sepsis. Crit Care Med 2014; 42:2409-17. 
doi: https://doi.org/10.1097/CCM.0000000000000509

13. Cantey JB, Patel SJ. Antimicrobial stewardship in the NICU. Infect Dis Clin North Am 2014; 28:24761. doi: https://doi.org/10.1016/j.idc.2014.01.005

14. Thapa S, Sapkota LB.Changing trend of neonatal septicemia and antibiotic susceptibility pattern of isolates in Nepal.IJPEDI 2019; 1-7. doi: https://doi.org/10.1155/2019/3784529

15. Clinical and Laboratory Standard Institute (CLSI). Performance standard for antimicrobial susceptibility testing: twenty-seven informational supplement M100-S27.

CLSI; 2017.https://clsi.org/media/1469/m100s27_sample.pdf

16. Seyal T, Husnain F, Anwar A. Audit of neonatal morbidity and mortality at neonatal unit of Sir Gangaram hospital Lahore. Annals of King Edward Medical University, Lahore Pakistan 2011: 17(1);9-13 No doi

17. Jalil F. Perinatal health in Pakistan: a review of current situation. Acta Paediatrica 2004; 93:1273-9. doi: http://dx.doi.org/10.1080/08035250410017022

18. Macharashvili N, Kourbatova E, Butsashvili M, et al. Etiology of neonatal blood stream infections in Tbilisi, Republic of Georgia. Int J Infect Dis 2009; 13:499-505.

doi: http://dx.doi.org/10.1016/j.ijid.2008.08.020

19. Aftab R, Iqbal I. Bacteriological agents of neonatal sepsis in NICU at Nishtar Hospital Multan. JCPSP 2006; 16:216-9. doi: https://doi.org/3.2006/JCPSP.216219

20. Shrestha S, Adhikari N, Shakya D, Manandhar L, Chand A, Shah S. Bacteriological profile of neonatal blood cultures at Patan hospital. J. Nepal Paediatr. Soc 2008; 26:9-12. No doi

21. Marzban A, Samaee H, Mosavinasab N. Changing trend of empirical antibiotic regimen: Experience of two studies at different periods in a neonatal intensive care unit in Tehran, Iran. Acta Med Iran. 2010; 48:312-5. https://www.ncbi.nlm.nih.gov/pubmed/21287464

22. Rai NS, Khan S, Waseem T, et al. Analysis of bacterial pathogens and their antibiotic susceptibility, A study at government tertiary care hospital, Karachi. JDUHS2013;7(1):35-40. https://pdfs.semanticscholar.org/367a/9d4dae7a8536221fcfb086851b51531d8c7b.pdf

23. Shaw CK, Shaw P, Thapalial A. Neonatal sepsis bacterial isolates antibiotics susceptibility patterns at a NICU in a tertiary care hospital in western Nepal. A retrospective analysis. Kathmandu Uni Med J 2007; 18:153-6. www.ncbi.nlm.nih.gov/pubmed/18604011

24. Hussain M, Aurakzai AA, Irshad M and Ullah I. Frequency of various bacteria and their antibiotic sensitivity in neonatal sepsis. Professional Med J 2018; 25(11):1683-88. doi: 10.29309/TPMJ/18.4719

25. S Jick. Ciprofloxacin safety in a pediatric population. Pediatr Infect Dis J 1997; 16(1):130-4. doi: https://doi.org/10.1097/00006454-199701000-00037

26. Nepal HP, Acharya A, Gautam R, et al. Bacteriological profile of neonatal septicemia cases and the antimicrobial resistance pattern in a tertiary care hospital of central Nepal. IJBR 2013;4(1):26-31. https://ssjournals.com/index.php/ijbr/article/view/793

27. Dalal P, Gathwala G, Gupta M, et al. Bacteriological profile and antimicrobial sensitivity pattern in neonatal sepsis: a study from North India. Int J Res Med Sci. 2017; 5(4):1541-45. doi: http://dx.doi.org/10.18203/2320-6012.ijrms20171261

28. Amad M, Yasrab M, Khushdil A, et al. Neonatal sepsis in a tertiary care hospital; Bacteriological profile \& its antimicrobial sensitivity. Pak Armed Forces Med J 2018; 68(6): 1654-58. https://www.pafmj.org/index.php/PAFMJ/article/view/2566

29. Samudio GC, Monzón R, Ortiz LM, et al. Late onset neonatal sepsis in an intensive care neonatal unit: etiological agents and most frequent location. Rev. Chil. Infectol.

2017;35(5). https://europepmc.org/abstract/med/30725002

30. Lebea M, Davies V. Evaluation of culture-proven neonatal sepsis at a tertiary care hospital in Johannesburg, South Africa. SAJCH. 2017;11(4):170-173

doi: http://dx.doi.org/10.7196/sajch.2017.v11i4.1310 